\title{
Mucositis-Induced Pain due to Barrier Dysfunction may have a Direct Effect on Nutritional Status and Quality of Life in Head and Neck Cancer Patients Receiving Radiotherapy
}

\author{
(D) Beste M. ATASOY,' (1) Kıvanç BEKTAŞ KAYHAN,² (D) Birsen DEMIREL, ${ }^{3}$ (D) Esra AKDENIZ ${ }^{4}$ \\ 'Department of Radiation Oncology, Marmara University Faculty of Medicine, İstanbul-Turkey \\ 2Department of Oral and Maxillofacial Surgery, İstanbul University Faculty of Dentistry, İstanbul-Turkey \\ ${ }^{3}$ Department of Nutrition and Dietetics, İstanbul Bilgi University Faculty of Health Sciences, İstanbul-Turkey \\ ${ }^{4}$ Department of Medical Education, Marmara University Faculty of Medicine, İstanbul-Turkey
}

\section{OBJECTIVE}

To maintain the barrier function against mucositis-induced pain and to improve the nutritional status and quality of life in head and neck cancer patients during radiotherapy.

\section{METHODS}

All patients $(n=30)$ used oral gel to reduce mucositis-induced pain. Patients were examined weekly for the severity of mucositis, pain and nutritional status. The quality of life parameters was measured at the beginning and at the end of treatment. There was no restriction for pain killers against mucositis.

\section{RESULTS}

The only significant factor affecting the severity and frequency of mucositis was the cumulative radiation dose $(\mathrm{p}<0.001)$. Despite the regular use of oral gel, weight loss was observed in $65 \%$ of the patients. There was no difference concerning the severity of mucositis, cumulative radiation doses, or mean dose of oral mucosa between patients with no risk or at risk, according to SGA. However, self-assessment pain scores were significantly better in the well-nourished group ( $\mathrm{p}=0.05$ vs. 0.015 ) with better scores for dry mouth $(\mathrm{p}=0.043)$, social eating $(\mathrm{p}=0.006)$, swallowing difficulties $(\mathrm{p}=0.001)$ and communication $(\mathrm{p}=0.049)$.

\section{CONCLUSION}

Supporting the barrier function alone does not help to reduce the severity and frequency of mucositis, nor the oral pain in high doses. Mucositis-induced pain may have a direct effect on malnutrition risk and quality of life in head and neck cancer patients. Powerful strategies are required to manage pain due to mucositis during curative radiotherapy.

Keywords: Head and neck cancer; hyaluronic acid; nutrition; polyvinyl prolidone; quality of life; radiotherapy. Copyright $\odot$ 2020, Turkish Society for Radiation Oncology

\section{Introduction}

Oral mucositis is one of the most frequent side-effects of head and neck radiotherapy.[1] Mucosal inflamma- tion and ulceration cause pain and swallowing difficulties during radiotherapy and may have a detrimental effect on treatment, causing prolongation with unintended interruptions.[2,3] Several strategies to reduce 
the severity and frequency of mucositis are described in the literature, but none of them are completely effective or strongly recommended.[4-7] The total radiation dose for oral mucosa is one of the most important factors in mucositis. Therefore, a severe side-effect is inevitable during definitive radiotherapy.[6] Mucositis-induced pain may adversely affect nutritional status, especially the oral health-related quality of life of patients receiving curative treatment. $[8,9]$

In this prospective single-arm study, we aimed to maintain the barrier function against mucositis-induced pain with an oral gel containing glycyrrhetinic acid, hyaluronic acid and polyvinylpyrrolidone in head and neck cancer patients during radiotherapy. $[6,10]$ This oral gel has previously been described as effective in reducing pain during chemotherapy, and in a few radiotherapy studies.[11-13] In this study, our goal is to maintain nutritional status and quality of life by maintaining the mucosal barrier function and reducing oral pain.

\section{Materials and Methods}

\section{Ethical Considerations}

Ethics approval for this study was obtained from Marmara University School of Medicine Ethical Committee with the number 7037436-050.06.04-140018640. All volunteers signed consent forms after a full explanation of this clinical study.

\section{Patients and Settings}

Thirty patients diagnosed with head and neck cancer were included in this study. However, one patient died due to disease progression in the third week of radiotherapy. Thus, 29 volunteers were included in the analysis (loss rate: $3.3 \%$ ). The characteristics of the study group are summarized in Table 1. All patients were examined by a dentist experienced in head and neck radiotherapy (KBK) for oral hygiene evaluation and periodontal and dental treatment was carried out if necessary, before radiotherapy. None of the volunteers reported any alcohol or tobacco usage during radiotherapy.

Radiotherapy was applied in a linear accelerator with $6 \mathrm{MV}$ photon energy using the volumetric arch technique to patients with curative intent in a median six weeks, with a mean dose of $66 \mathrm{~Gy}$ (range, 60 to 70 Gy). Each patient received the treatment with intensity-modulated radiotherapy planning (IMRT). Most of the patients received concurrent weekly cisplatinbased chemotherapy $(83.3 \%)$. Oral mucosa for each
Table 1 Demographics of the patients and treatments characteristics

\begin{tabular}{|c|c|}
\hline Variable & Mean (SD); Min-Max \\
\hline \multicolumn{2}{|l|}{ Gender } \\
\hline Male & $24(82 \%)$ \\
\hline Female & $5(28 \%)$ \\
\hline Age (years) & 56.79 (13.57); 23-87 \\
\hline \multicolumn{2}{|l|}{ Location of tumor } \\
\hline Oral cavity & 11 \\
\hline Nasopharynx & 7 \\
\hline Larynx & 6 \\
\hline Paranasal sinuses & 3 \\
\hline Oropharynx & 1 \\
\hline Primary unknown neck & 1 \\
\hline \multicolumn{2}{|l|}{ Chemotherapy } \\
\hline Neoadjuvant & $6(20 \%)$ \\
\hline Concurrent & $25(83.3 \%)$ \\
\hline Mean dose of radiotherapy & 66 Gy (60-70 Gy) \\
\hline Mean dose of oral mucosa (Gy) & 36.84 (23.72); 3.1-62.2 \\
\hline \multirow[t]{2}{*}{ Volume of oral mucosa (cc) } & 135.11 (28.14); 81.9-201.37 \\
\hline & Median (IQR); Min-Max \\
\hline V10 (\%) & $82.33(30.38) ; 0-100$ \\
\hline V20 (\%) & 75.22 (32.98); 0-100 \\
\hline V30 (\%) & $59.92(31.84) ; 0-100$ \\
\hline V40 (\%) & $48.25(32.83) ; 0-100$ \\
\hline V50 (\%) & $38.02(34.01) ; 0-100$ \\
\hline
\end{tabular}

SD: Standard deviation; V10-50: Percentage of oral mucositis volume that receive the related doses of radiation in Gray

patient was countered by a radiation oncologist for organs at risk, including the teeth and buccal mucosa. The mean volume of oral mucosa was revealed with a $3 \mathrm{D}$ radiotherapy planning system (Eclipse v11.0) and it was $132.69 \mathrm{cc}$ (SD 24.94; range, 81.9 to $201.37 \mathrm{cc}$ ). The percentage of the mean volume received radiation dose (in Gy) by oral mucosa (V10 to V50) was $40.19 \%$ (SD 23.72\%; range, 3.1 to $100 \%$ ) (Table 1 ).

Oral mucositis was measured and graded weekly from the beginning to the end of radiotherapy. The prevalence of severe oral mucositis was documented by Common Toxicity Criteria v3.0.[14] A grade of three or higher indicates the prevalence of severe mucositis.

All patients were assessed weekly for other sideeffects by a radiation oncologist (BMA), and for oral and dental care (physical changes in mucosa, gingiva and teeth) by a dentist (KBK), and for nutritional status and treatment by a dietitian (BD) using the subjective global assessment test (SGA).[15] The oral gel containing glycyrrhetinic acid, hyaluronic acid and polyvinylpyrrolidone (GelClair ${ }^{\odot}$ ) was provided from 
Helsinn Pharmaceutical Company without any charge. The oral gel was used to coat the ulcerated oral mucosa surface and to reduce mucositis-induced pain during eating. The application of oral gel was started at the 12 Gy of radiotherapy when the clinical symptoms biologically start.[16] Therefore, patients used oral gel before every meal, at least three times a day. They used oral gel for one minute for each administration and performed self-measurement using a sand timer. Regular usage was checked weekly via patients and/or caregivers' paper-based reports. The self-assessment visual analog score (VAS) was used for assessing oral pain weekly during radiotherapy.[17] Pain scores ranging from 0 to 10 on a continuous scale were measured $(0=$ no pain to $10=$ very painful). There was no restriction for painkiller usage, and patients did not use any other strategy to reduce the mucositis. Oral healthrelated quality of life was assessed using the EORTC QoL-HN35 questionnaire at the beginning and at the end of radiotherapy.[18]

\section{Statistical Analysis}

For descriptive purposes, numerical variables were summarized using means and standard deviations, or medians and interquartile ranges according to the distribution. The distribution of the continuous variables was investigated using the Shapiro Wilks test, QQ, PP plots, skewness and kurtosis values. Patients' mucositisrelated symptoms were measured each week of radiotherapy. Mucositis was classified as being severe ( 2 and 3 ) or not severe ( 0 and 1$)$. This reasoning warranted the decision to dichotomize the outcomes, as well as the choice of threshold. The proportion of severe mucositis was tested using the Cochran-Armitage test for trend. A longitudinal study design, with repeated measures, was used. Changes in VAS scores over time were assessed. Patients' oral mucosa and VAS were assessed at six-time points. Generalized estimating equations (GEE) were used to analyze the predictive factors of VAS scores. Patients were also analyzed after being divided according to malnutrition. Thus, the Wilcoxon signed-rank test was used to examine the differences in the prevalence of oral mucositis related symptoms (revealed by the EORTC QoLHN35 questionnaire), such as pain, swallowing, speech, social eating, communication and altered taste) within groups across different time-points. It was also of interest, given patients' pain status (no/yes) at the beginning of the therapy, to see whether oral mucositis related symptoms changed concerning time was investigated. The McNemar test was used to detect whether the nutritional assessment test SGA (no risk=SGA A/under risk=SGA B or $\mathrm{C}$ ) proportion changed between the beginning and the end of this study. Another analysis was also carried out looking at weight loss. The mean percentage of weight loss was $5 \%$, and groups were split by weight loss $<5 \%$ vs. $\geq 5 \%$. These statistical tests were performed with $\mathrm{R}$ 3.5.3 (R Core Team [2019]; R: A language and environment for statistical computing; R Foundation for Statistical Computing, Vienna Austria; URL http:// www.R-project.org/). A p-value of $<0.05$ was considered statistically significant.

\section{Results}

\section{Mucositis and Pain}

The prevalence and proportion of severe oral mucositis increased from week one to week five, peaked at week five, then decreased until the end of radiotherapy, as expected. A significant linear increasing trend for severe oral mucositis was found by the Cochran-Armitage linear trend test $(p<0.001)$ (Table 2). Meanwhile, oral mucositis-induced pain increased each week from the beginning to the end of radiotherapy $(\mathrm{p}<0.001)$. The only significant predictor for changes in VAS scores was the cumulative radiation doses of radiotherapy $(\mathrm{p}<0.001)$ (Table 3).

\section{Nutritional Status and Quality of Life}

There was a significant increase in the prevalence of patients' mucositis (64.3\%) who become at risk (SGA $\mathrm{B}$ or $\mathrm{C})$ at the end of radiotherapy $(\mathrm{p}<0.001)$ (Table 4$)$.

Table 2 Frequencies and prevalence of the severe oral mucositis concerning weeks of radiotherapy

\begin{tabular}{|c|c|c|c|c|c|c|c|c|}
\hline & & Week 1 & Week 2 & Week 3 & Week 4 & Week 5 & Week 6 & P value* \\
\hline None-severe & Count & 29 & 27 & 19 & 12 & 21 & 13 & $<0.001$ \\
\hline Grade 1-2 & Percent & $97 \%$ & $90 \%$ & $63 \%$ & $40 \%$ & $38 \%$ & $46 \%$ & \\
\hline Severe & Count & 1 & 3 & 11 & 18 & 18 & 15 & \\
\hline Grade 3 & Percent & $3 \%$ & $10 \%$ & $37 \%$ & $60 \%$ & $62 \%$ & $54 \%$ & \\
\hline
\end{tabular}

*: Cochran-Armitage linear trend test 
Table 3 Predictors for the changes in VAS scores

\begin{tabular}{|c|c|c|c|c|c|c|}
\hline Variable & Coef. & Std. Err. & $\begin{array}{l}\text { Lower } \\
(95 \% \mathrm{CI})\end{array}$ & $\begin{array}{l}\text { Upper } \\
(95 \% \mathrm{CI})\end{array}$ & $\begin{array}{c}\text { Z } \\
\text { (Wald test) }\end{array}$ & $\mathbf{p}$ \\
\hline Oral pain at the beginning of radiotherapy (Yes) & -0.462 & 0.650 & -1.735 & 0.812 & 0.505 & 0.477 \\
\hline CCRT (Yes) & 0.996 & 1.139 & -1.236 & 3.227 & 0.765 & 0.382 \\
\hline Volume of oral mucosa (135 cc) & 0.010 & 0.0117 & -0.013 & 0.033 & 0.765 & 0.382 \\
\hline Mean dose of oral mucosa (36.8 Gy) & 0.022 & 0.020 & -0.017 & 0.061 & 1.18 & 0.277 \\
\hline Cumulative radiation dose & 0.560 & 0.117 & 0.331 & 0.789 & 22.94 & $<0.001$ \\
\hline
\end{tabular}

VAS: Visual analogue score; CCRT: Concurrent chemoradiotherapy

\begin{tabular}{|c|c|c|c|}
\hline \multirow[t]{2}{*}{ Table 4} & \multicolumn{3}{|c|}{$\begin{array}{l}\text { Changes of the prevalence of malnutrition at } \\
\text { the beginning and end of this study according } \\
\text { to SGA }\end{array}$} \\
\hline & End of $\mathrm{r}$ & therapy & \\
\hline $\begin{array}{l}\text { Beginning of } \\
\text { radiotherapy }\end{array}$ & $\begin{array}{l}\text { No risk } \\
\text { (SGA A) }\end{array}$ & $\begin{array}{l}\text { Under risk } \\
\text { (SGA B or C) }\end{array}$ & $\mathbf{p}$ \\
\hline No risk & $10(35.7 \%)$ & $18(64.3 \%)$ & $<0.001$ \\
\hline Under risk & $0(0 \%)$ & $1(100 \%)$ & \\
\hline
\end{tabular}

SGA: Subjective global assessment

The mean percentage of weight loss was $4.95 \%$. There was no difference concerning the severity of mucositis, cumulative radiation doses or mean dose of oral mucosa between patients $<5 \%$ and $\geq 5 \%$ weight loss or SGA A and SGA B and C. On the other hand, the VAS score was worse in the SGA B and C group of patients (Fig. 1).

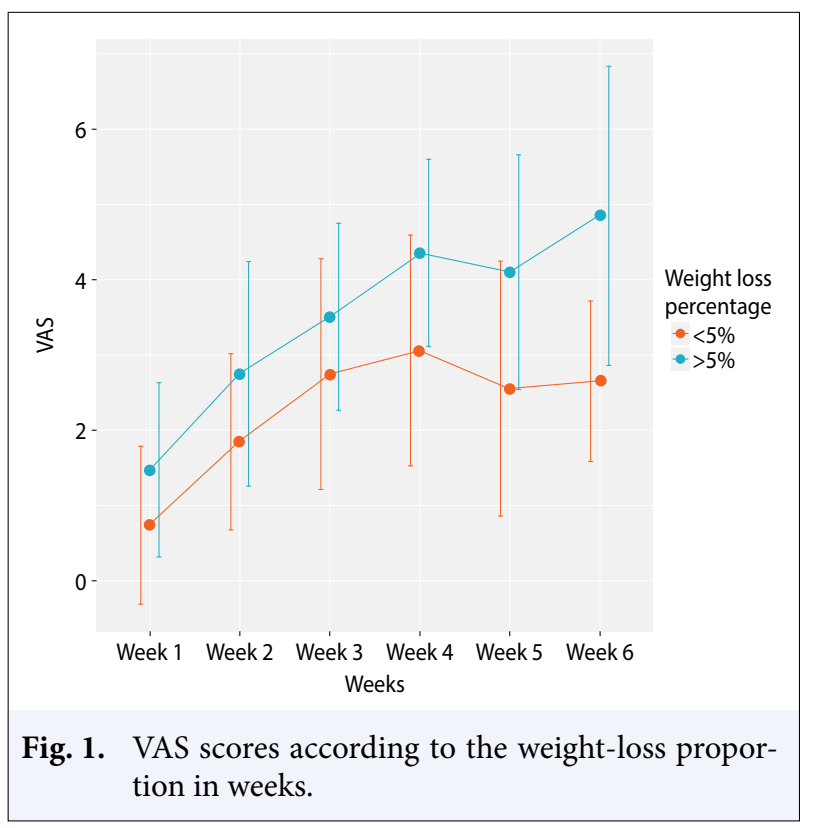

Oral health-related quality of life parameters worsened at the end of radiotherapy in all patients. Although analysis showed that pain ( $\mathrm{p}=0.01$ vs $\mathrm{p}=0.02)$, mouth pain ( $\mathrm{p}=0.123$ vs $\mathrm{p}=0.07)$, talking difficulties ( $\mathrm{p}=0.06 \mathrm{vs}$ $\mathrm{p}=0.001$ ), swallowing difficulties ( $\mathrm{p}=0.09$ vs $\mathrm{p}=0.001$ ), social eating difficulties $(\mathrm{p}=0.176 \mathrm{vs} \mathrm{p}=0.006)$, communication ( $\mathrm{p}=0.549 \mathrm{vs} \mathrm{p}=0.049$ ), taste altering ( $\mathrm{p}=0.004$ vs $\mathrm{p}=0.000)$ and dry mouth $(\mathrm{p}=0.05 \mathrm{vs} \mathrm{p}=0.04)$ were significantly worse in patients with $\geq 5 \%$ weight loss (SGA B or C) (Table 5).

Patients were split according to the mean percentage of weight loss $(\geq 5 \%)$. The severity of mucositis was not different between groups according to V40, V50 of the oral mucosa. However, VAS scores were lower in the well-nourished group of patients. Quality of life parameters was also significantly better in this group of patients (Table 6).

\section{Discussion}

Mucositis is a dose-limiting and common side-effect of head and neck radiotherapy.[1-3] It is not possible to maintain the integrity of the mucosa before the end of treatment. There are mainly two ways to reduce the effects of mucositis during head and neck radiotherapy. One is to reduce the volume of the high dose area of the mucosa, and another is to use medication, such as protective agents, anti-inflammatory agents and painkillers.[4-6] Due to the primary tumor side and treatment protocols, and despite modern techniques, it is not always possible to reduce the mucosal volume receiving high doses. Moreover, none of the recommendations for the medication fully work for severe mucositis. The Multinational Society for Supportive Care in Cancer (MASCC) recommends benzydamine for high-level treatment of mucositis to reduce and improve radiotherapy related mucositis.[5,6,19] We aimed to use an oral gel that coats the damaged mucosal area to decrease the severity of mucositis and 
Table 5 Comparisons of the EORTC QoLHN35 oral health-related parameters between the beginning and the end of the radiotherapy

\begin{tabular}{lccc}
$\begin{array}{l}\text { Variable } \\
\text { Individual symptom }\end{array}$ & $\begin{array}{c}\text { Beginning of radiotherapy } \\
\text { Median (IQR); Min-Max }\end{array}$ & $\begin{array}{c}\text { End of radiotherapy } \\
\text { Median (IQR); Min-Max }\end{array}$ \\
\hline Mouth pain & $8.33(16.6) ; 0-50$ & $33.3(49.97) ; 0-83.3$ & $\mathbf{p}^{\mathbf{a}}$ \\
Talking difficulties & $0(44.4) ; 0-100$ & $77.8(58.28) ; 22.2-100$ & $<0.001$ \\
Swallowing difficulties & $8.33(16.62) ; 0-58.3$ & $33.3(66.7) ; 0-100$ & $<0.001$ \\
Social eating difficulties & $0(8.33) ; 0-50$ & $16.6(26.17) ; 0-100$ & 0.001 \\
Communication & $0(0) ; 0-60$ & $0(23.3) ; 0-80$ & 0.036 \\
Taste altered & $100(0) ; 100-100$ & $0(33.3) ; 0-100$ & $<0.001$ \\
\hline
\end{tabular}

a: Wilcoxon signed-rank test

Table 6 Severity of mucositis, VAS and oral health-related quality of life parameters changes during treatment split by percentage of weight-loss

\begin{tabular}{|c|c|c|c|c|}
\hline & \multicolumn{4}{|c|}{ Weight-loss at the end of radiotherapy } \\
\hline & \multicolumn{2}{|c|}{$<5 \%(n=12)$} & \multicolumn{2}{|c|}{$\geq 5 \%(n=17)$} \\
\hline & $\mathbf{Z}$ & $\mathbf{p}$ & $\mathbf{Z}$ & $\mathbf{p}$ \\
\hline V40 & $-3.059 d$ & 0.002 & $-3.180 d$ & 0.001 \\
\hline V50 & -3.059 & 0.002 & $-3.296 d$ & 0.001 \\
\hline Mucositis severity & $-3.002 c$ & 0.003 & $-3.464 c$ & 0.001 \\
\hline VAS & $-1.963 c$ & 0.05 & $-2.429 c$ & 0.015 \\
\hline \multicolumn{5}{|c|}{ EORTC QoL HN35 parameters } \\
\hline Pain (Q1-4) & $-2.448 c$ & 0.014 & $-2.231 c$ & 0.026 \\
\hline Mouth pain & $-1.542 c$ & 0.123 & $-1.792 c$ & 0.073 \\
\hline Talking difficulties & $-1.869 c$ & 0.062 & $-3.366 c$ & 0.001 \\
\hline Swallowing difficulties & $-1.689 c$ & 0.091 & $-3.208 c$ & 0.001 \\
\hline Social eating difficulties & $-1.355 c$ & 0.176 & -2.746 & 0.006 \\
\hline Communication & $-0.535 c$ & 0.593 & $-1.970 c$ & 0.049 \\
\hline Taste altered & $-2.850 d$ & 0.004 & $-3.700 d$ & 0.000 \\
\hline Dry mouth & $-1.933 c$ & 0.053 & $-2.028 c$ & 0.043 \\
\hline
\end{tabular}

VAS: Visual analogue score

the pain it causes. Oral mucositis becomes worse in the later weeks of radiotherapy. In our study, we observed mucositis severity and frequency as expected in high-dose radiotherapy. The goals of this study are to reduce mucositis-induced pain, to protect against weight-loss and improve quality of life with oral gel. In the literature, there are a couple of randomized control studies to test the barrier function against mucositis. Two prospective trials found no difference in mucositis incidence comparing standard care.[11,20] In their randomized study, Barber et al.[11] found that the barrier function is not more effective than Sucralfate and Mucaine in relieving the pain associated with radiotherapy-induced oral mucositis. However, Hadjieva et al.[13] found a positive effect of the gel on mucositis in their randomized study. Our results showed that the coating agent itself could not decrease the frequency and severity of radiation-induced mucositis against a definitive high dose of radiotherapy ( $\geq 60 \mathrm{~Gy}$ ).

It is difficult to assess pain as a symptom due to its subjective nature.[21] Therefore, we used a self-assessment method of VAS to measure pain in our patients. [17] Mucositis-induced pain increased week by week, and the difference between the initial period and the end of radiotherapy was significant $(\mathrm{p}<0.001)$. This result may reflect inadequate pain relief. We found that concurrent chemotherapy, the mucosal volume of high doses, oral mucosa volume and oral pain at the beginning of radiotherapy has no impact on VAS scores expect cumulative radiation dose $(\mathrm{p}<0.001)$. 
There is not a single type of pain in radiotherapy for head and neck cancer patients.[21] Therefore, we asked about previous pain experience before radiotherapy and used the oral health-related QoL parameters of the EORTC HN35 questionnaire.[18] Pain (Q1-Q4), mouth pain, talking difficulties, swallowing difficulties, social eating difficulties, communication, altered taste and dry mouth all got significantly worse et the end of radiotherapy. Furthermore, more than $60 \%$ of the patients became at risk of malnutrition. What is interesting is that there was no difference according to the cumulative radiation dose (V40 and V50) of the oral mucosa or mucosal severity between patients according to nutritional status. However, the VAS score was lower in well-nourished patients (Table 6, Fig. 1). All parameters except altered taste were significantly worse in the malnutrition group. Hence, we think that the key point is to reduce mucositis-induced pain to maintain quality of life and nutritional status in head and neck radiotherapy.

In this study, we followed a multidisciplinary approach for the evaluation of mucositis-induced pain by radiation using an oncologist, dentist and dietitian. However, there are some limitations to this study. This had no control group to compare the standard of care, and a lack of long-term follow-up to observe late toxicities.

\section{Conclusion}

Severe mucositis incidence and frequency cannot be reduced in high definitive doses of radiotherapy. Mucositis-induced pain may have a direct effect on malnutrition risk and quality of life during radiotherapy. Therefore, it is crucial to find effective solutions against mucositis-induced pain concerning maintaining the nutritional status and quality of life of head neck cancer patients.

Acknowledgement: We thank Miss Nargül Türkmen, the assistant manager, for her support to complete this study. We also thank to Helsinn Pharmaceutical Company which provided the oral gel without any charge.

Peer-review: Externally peer-reviewed.

Conflict of Interest: All authors declared no conflict of interest.

Ethics Committee Approval: Marmara University School of Medicine Ethical Committee with the number 7037436050.06.04-140018640.

Financial Support: None declared.

Authorship contributions: Concept - B.M.A.; Design B.M.A., K.B.K.; Supervision - B.M.A., K.B.K., B.D.; Fund- ing - None; Materials - B.M.A., K.B.K., B.D., E.A.; Data collection and/or processing - B.M.A., K.B.K., B.D., E.A.; Data analysis and/or interpretation - B.M.A., K.B.K., B.D., E.A.; Literature search - B.M.A., K.B.K., B.D., E.A.; Writing - B.M.A., B.D.; Critical review - B.M.A., K.B.K., B.D., E.A.

\section{References}

1. Trotti A, Bellm LA, Epstein JB, Frame D, Fuchs HJ, Gwede CK, et al. Mucositis incidence, severity and associated outcomes in patients with head and neck cancer receiving radiotherapy with or without chemotherapy: a systematic literature review. Radiother Oncol 2003;66(3):253-62.

2. Bese NS, Hendry J, Jeremic B. Effects of prolongation of overall treatment time due to unplanned interruptions during radiotherapy of different tumor sites and practical methods for compensation. Int J Radiat Oncol Biol Phys 2007;68(3):654-61.

3. Russo G, Haddad R, Posner M, Machtay M. Radiation treatment breaks and ulcerative mucositis in head and neck cancer. Oncologist 2008;13(8):886-98.

4. Ranna V, Cheng KKF, Castillo DA, Porcello L, Vaddi A, Lalla RV, et al; Mucositis Study group of the Multinational Association of Supportive Care in Cancer/ International Society for Oral Oncology (MASCC/ ISOO). Development of the MASCC/ISOO clinical practice guidelines for mucositis: an overview of the methods. Support Care Cancer 2019;27(10):3933-48.

5. Lalla RV, Bowen J, Barasch A, Elting L, Epstein J, Keefe DM, et al; Mucositis Guidelines Leadership Group of the Multinational Association of Supportive Care in Cancer and International Society of Oral Oncology (MASCC/ISOO). MASCC/ISOO clinical practice guidelines for the management of mucositis secondary to cancer therapy. Cancer 2014;120(10):1453-61.

6. De Sanctis V, Bossi P, Sanguineti G, Trippa F, Ferrari $\mathrm{D}$, Bacigalupo A, et al. Mucositis in head and neck cancer patients treated with radiotherapy and systemic therapies: Literature review and consensus statements. Crit Rev Oncol Hematol 2016;100:147-66.

7. Chung YL, Pui NNM. Confounding factors associated with oral mucositis assessment in patients receiving chemoradiotherapy for head and neck cancer. Support Care Cancer 2017;25(9):2743-51.

8. Lee SC, Wang TJ, Chu PY. Predictors of weight loss during and after radiotherapy in patients with head and neck cancer: A longitudinal study. Eur J Oncol Nurs 2019;39:98-104.

9. Jung YS, Park EY, Sohn HO. Oral Health Status and Oral Health-related Quality of Life According to Presence or Absence of Mucositis in Head and Neck Cancer Patients. J Cancer Prev 2019;24(1):43-7. 
10. Buchsel PC. Polyvinylpyrrolidone-sodium hyaluronate gel (Gelclair): a bioadherent oral gel for the treatment of oral mucositis and other painful oral lesions. Expert Opin Drug Metab Toxicol 2008;4(11):1449-54.

11. Barber C, Powell R, Ellis A, Hewett J. Comparing pain control and ability to eat and drink with standard therapy vs Gelclair: a preliminary, double centre, randomised controlled trial on patients with radiotherapy-induced oral mucositis. Support Care Cancer 2007;15(4):427-40.

12. Innocenti M, Moscatelli G, Lopez S. Efficacy of gelclair in reducing pain in palliative care patients with oral lesions: preliminary findings from an open pilot study. J Pain Symptom Manage 2002;24(5):456-7.

13. Hadjieva T, Cavallin-Ståhl E, Linden M, Tiberg F. Treatment of oral mucositis pain following radiation therapy for head-and-neck cancer using a bioadhesive barrier-forming lipid solution. Support Care Cancer 2014;22(6):1557-62.

14. National Cancer Institude. Common Terminology Criteria for Adverse Events v3.0 (CTCAE). Available from: https://ctep.cancer.gov/protocolDevelopment/ electronic_applications/docs/ctcaev3.pdf. Accessed, January 2, 2020.

15. Detsky AS, McLaughlin JR, Baker JP, Johnston N, Whittaker S, Mendelson RA, et al. What is subjective global assessment of nutritional status? JPEN J Parenter Enteral Nutr 1987;11(1):8-13.

16. Bentzen SM, Saunders MI, Dische S, Bond SJ. Radiotherapy-related early morbidity in head and neck can- cer: quantitative clinical radiobiology as deduced from the CHART trial. Radiother Oncol 2001;60(2):123-35.

17. Price DD, McGrath PA, Rafii A, Buckingham B. The validation of visual analogue scales as ratio scale measures for chronic and experimental pain. Pain 1983;17(1):45-56.

18. Sherman AC, Simonton S, Adams DC, Vural E, Owens B, Hanna E. Assessing quality of life in patients with head and neck cancer: cross-validation of the European Organization for Research and Treatment of Cancer (EORTC) Quality of Life Head and Neck module (QLQ-H\&N35). Arch Otolaryngol Head Neck Surg 2000;126(4):459-67.

19. Zadik Y, Arany PR, Fregnani ER, Bossi P, Antunes HS, Bensadoun RJ, et al; Mucositis Study Group of the Multinational Association of Supportive Care in Cancer/International Society of Oral Oncology (MASCC/ISOO). Systematic review of photobiomodulation for the management of oral mucositis in cancer patients and clinical practice guidelines. Support Care Cancer 2019;27(10):3969-83.

20. Flook C, Calman F, Mant M, Subramanian R, O'Connell M. GELCLAIR ${ }^{\circledR}$ vs benzydamine in a randomised controlled study in patients with oral mucositis due to radical radiotherapy. Abstracts of the $17^{\text {th }}$ MASCC International Symposium. Support Care Cancer 2005;13(6):401-83.

21. Bossi P, Giusti R, Tarsitano A, Airoldi M, De Sanctis V, Caspiani O, et al. The point of pain in head and neck cancer. Crit Rev Oncol Hematol 2019;138:51-9. 